\title{
Comparative study of ground layers of nineteenth century Portuguese Paintings
}

\author{
Bordalo, R. , Lorena, M*, Cardoso, A.., Mirão, J. , Santos, L. ${ }^{* *}$ and Candeias, A.* \\ * Laboratório HERCULES, Universidade de Évora, Palácio do Vimioso, Largo Marquês de Marialva, 8, \\ 7000-809 Évora, PORTUGAL \\ ** Laboratório José de Figueiredo, Direção Geral do Património Cultural, Rua das Janelas Verdes, 37, 1300- \\ 001 Lisbon, PORTUGAL \\ *** Instituto Superior Técnico, Av. Rovisco Pais, 1, 1049-001 Lisbon, PORTUGAL
}

Email: rmbordalo@uevora.pt

Western art in the nineteenth century was profuse in movements, and artists were more experimental than ever before. The nineteenth century also brought numerous novelties in painting materials and techniques. Traditional painting materials from past centuries were used at the same time as new contemporary materials were discovered and experimented. The paintings' ground layer is usually hidden from sight but it is not without importance since it has a considerable impact in the stability and final appearance of the painting. The ground layer was traditionally prepared by the painter by mixing animal glue as binder, lead white as white pigment and other white fillers. During the nineteenth century, and with the introduction of new white colour materials, the formulations of ground layers changed significantly.

This article describes the comparative characterization of the ground layers of eleven paintings dated from 1852 to 1884 by eight Portuguese painters: João Cristino da Silva (1829-1877), Tomás da Anunciação (18181879), António José Patrício (1827 - 1858), Miguel Ângelo Lupi (1826-1883), Marques de Oliveira (18531927), Alfredo Keil (1850-1907), Carlos Reis (1863-1940), Francisco Metrass (1825-1861), Luís de Meneses (1820-1878). The paintings are part of the permanent exhibition of the National Museum of Contemporary Art (Chiado Museum) in Lisbon. Even though well-known, some of these painters' works were never previously subjected to material study.

The characterization of the painting materials was performed using an optical microscope LEICA DM2500M, a scanning electron microscope of variable vacuum HITACHI 3700N coupled with an energydispersive X-R spectrometer BRUKER Xflash 5010SDD, a $\mu$-Raman HORIBA Xplora coupled with an Olympus BX41 microscope and a $\mu$-FTIR Nicolet Nexus 670 FTIR with Continuum IR microscope.

The study allowed the characterization of the several ground layers (Fig. 1) including thickness and materials, and its distinction by painter. Although the ground layers present some similarities, such as the presence of coarse calcite and lead white, they are quite diverse concerning their thickness, number and their content with typical variation of barium white and zinc white, used as fillers, and other impurities in different percentages. Barium white - known since the beginning of the century - is the filler by excellence, followed by calcite and kaolin. Nevertheless, zinc white - known since 1834 as pigment - was only used in the ground layer by one painter showing, thus, how slow the use and replacement of new materials by painters can be.

The authors acknowledge National Museum of Contemporary Art (Chiado Museum) and Fundação para a Ciência e a Tecnologia for the grant SFRH/BPD/85259/2012. 


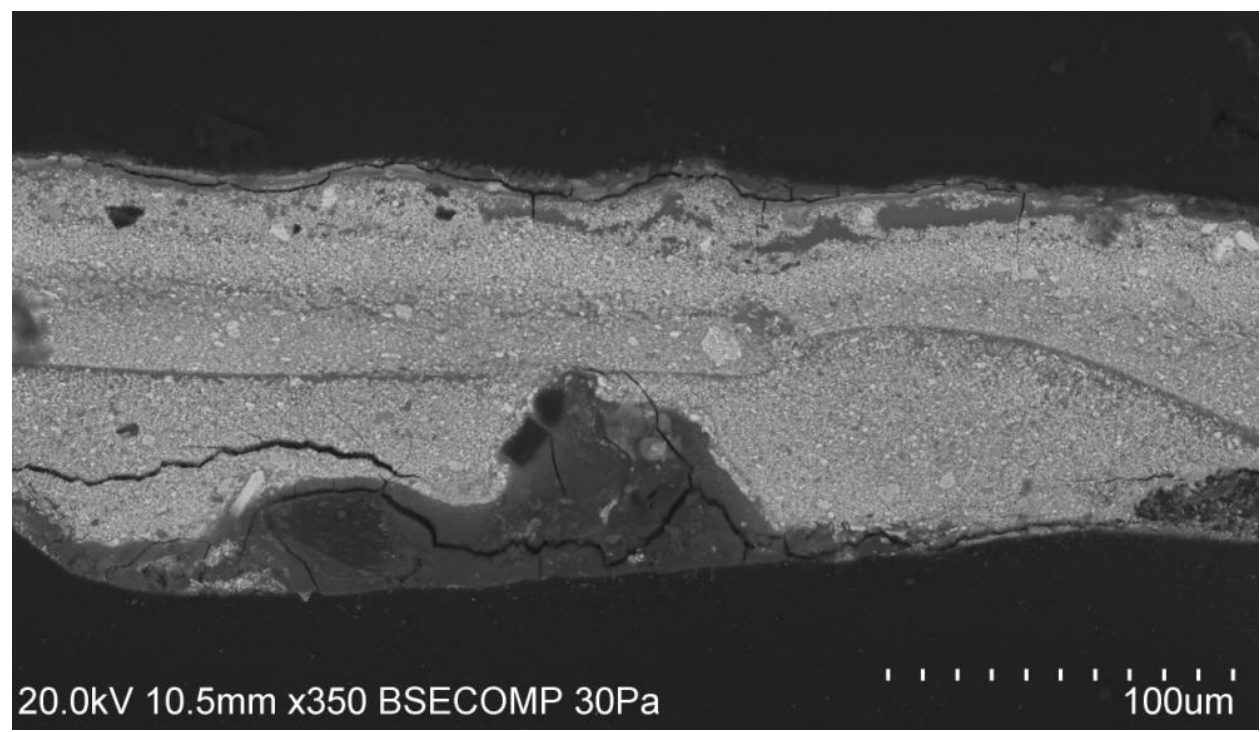

Figure 1. Microphotograph of a cross-section from the painting A Despedida (1858) by António José Patrício. 